\title{
ANÁLISE DO GRAU DE CONCENTRAÇÃO DA INDÚSTRIA AUTOMOBILÍSTICA BRASILEIRA E SUA RELAÇÃO COM A PARTICIPAÇÃO NO MERCADO ${ }^{1}$
}

\section{ANALYSIS OF THE DEGREE OF CONCENTRATION OF THE BRAZILIAN AUTOMOBILE INDUSTRY AND ITS RELATION WITH THE PARTICIPATION IN MARKET}

\author{
Wesley Vieira da Silva ${ }^{2}$ \\ Meire Maria Andrade Cavalari ${ }^{3}$ \\ Rosana Harder Onofre ${ }^{4}$ \\ Jansen Maia Del Corso ${ }^{5}$
}

\begin{abstract}
RESUMO:O presente estudo tem por objetivo fazer uma análise da evolução do segmento automobilístico no Brasil, considerando seu grau de concentração industrial e parcela de mercado, no período compreendido entre 1995 e 2005 . Utilizaram-se como método de análise, algumas medidas de concentração industrial, a saber: Razão de Concentração, Índice de Hirschman-Herfindahl e o Índice de Rosenbluth, visando traçar um panorama acerca da influência de fatos relevantes para as possíveis mudanças ocorridas na economia brasileira no período considerado. Os resultados auferidos a partir dos dados coletados evidenciam que houve uma elevada razão de concentração no início do período da análise qual vai diminuindo à medida que novas empresas são implantadas no setor e, gradativamente, vão aumentando seu volume de produção e, conseqüentemente, sua participação no mercado.
\end{abstract}

PALAVRAS-CHAVE: Medidas Concentração, indústria automobilística brasileira, participação mercado.

ABSTRACT:The objective of this paper was to analyse the evolution of the automobile segment in Brazil, considering its industry concentration level and market share, between 1995 and 2005. As analisys method, it was chosen some measures of industrial concentration such as: Concentration Ratio, Hirschman-Herfindahl Index and Rosenbluth Index, in order to show a perspective regarding the influence of relevant facts to possible changes which occurred in Brazilian economy in the considered period. The results obtained from the collected data make evident of a higher concentration ratio in the initial period of the analysis which decreases as the new incoming companies are installed in the industry and, gradually, have their production rate increasing, as well as it can be observed an increase in their market share.

KEY WORDS: Concentration measures, Brazilian Automobile Industry, Market Share

\footnotetext{
${ }^{1}$ Artigo Recebido em 07.10.2008. Revisado por pares em 07.10.2008. Recomendado em 02.12.2008 por Denise Del Pra Netto Machado (editora). Publicado em 08.12.2008. Organização Responsável pelo periódico: Universidade regional de Blumenau - FURB.

2 Professor do Programa de Pós-Graduação em Administração Estratégica da PUCPR wesley.vieira@pucpr.br ${ }^{3}$ Mestre pelo Programa de Pós-Graduação em Administração Estratégica da PUCPR. meiremack@onda.com.br

${ }^{4}$ Mestre pelo Programa de Pós-Graduação em Administração Estratégica da PUCPR. rosanaharder@hotmail.com

5 Professor do Programa de Pós-Graduação em Administração Estratégica da PUCPR del.corso@pucpr.br
} 


\section{INTRODUÇÃ̃O}

A concentração industrial pode ser analisada por meio do conhecimento da proporção da produção total controlada por um número pequeno de empresas em um determinado setor (HOFFMAN, 2006).

O grau de concentração industrial determinará se uma indústria específica caracteriza-se como um monopólio, oligopólio ou um mercado de concorrência equilibrada. As medidas de concentração industrial podem ser consideradas como um termômetro da concorrência das empresas de uma indústria.

Embora possa haver um elevado índice de concentração na avaliação da produção da indústria, poder-se-á constatar que nem sempre a empresa com o maior grau terá a maior fatia do mercado no que se refere às vendas dessa produção.

O objetivo deste trabalho, apoiado em alguns índices de concentração, é avaliar o grau de concentração da indústria automobilística no Brasil, investigando, concomitantemente, se há uma relação entre os índices de concentração e sua participação no mercado. Esta análise considera a produção e venda de veículos de passageiros e leve no período de 1995 a 2005, e a sua efetiva participação no mercado nacional. Busca mostrar ainda, a influência de fatos de caráter históricos e estratégicos bastante significativos para flutuações como, por exemplo, a entrada de novas concorrentes.

Num sentido amplo, entende-se o termo concentração industrial como um processo que consiste no aumento do controle exercido pelas empresas grandes sobre a atividade econômica. O grau de concentração sintetiza a estrutura produtiva, uma vez que incorpora tanto aspectos tecnológicos relacionados ao porte quanto à consolidação do poder de mercado de um setor (CARVALHO et al., 2003, p. 22). Pode-se dizer que o grau de concentração apresenta-se como uma dimensão significativa da estrutura de mercado, pois deve desempenhar importante papel na determinação do comportamento e do desempenho da empresa (GEORGE; JOLL, 1983, p. 136).

O trabalho encontra-se estruturado em cinco seções que podem ser sumarizadas como: a primeira refere-se a parte introdutória; a segunda trata do referencial teórico-empírico; a terceira enfoca a metodologia da pesquisa; a quarta traz a apresentação e análise dos dados e a quinta seção refere-se às considerações finais.

\section{REFERENCIAL TEÓRICO-EMPÍRICO}

A indústria automobilística é considerada uma das mais importantes atividades industriais do mundo moderno, não somente tomado o seu volume anual de produção, que chega a aproximadamente 50 milhões por ano (WOMACK; JONES; ROSS, 1992), mas também pela relevância de seus produtos para a vida diária do homem.

Conforme evidencia Guimarães (1982), foi por volta da metade da década de 50, em meio ao processo de internacionalização das indústrias mundiais de veículos, que o governo brasileiro, passou a atrair capital estrangeiro e trouxe a indústria automobilística para o Brasil. Essa indústria instalou-se no país precisamente em 1956, impulsionada pelo baixo custo da mão-de-obra brasileira, que proporcionava alguma vantagem comparativa em relação às demais indústrias situadas nos países desenvolvidos. 
Segundo Bertolini (2004), a importância dessa indústria é ainda maior quando associada às inovações tecnológicas e produtivas difundidas a partir do seu desenvolvimento, na medida em que a estrutura de organização da produção adotada por esta indústria serviu de modelo para muitas outras.

Com a aplicação do modelo do sistema de produção em massa, esse segmento industrial se consolidou a partir da concentração da produção de veículos nas mãos de um pequeno número de organizações. $\mathrm{Na}$ década de 60 , as três grandes companhias de automóveis dos Estados Unidos eram responsáveis por $94 \%$ da produção daquele país, enquanto na Alemanha quatro empresas fabricavam 91\% dos veículos, na França, 100\% da produção era proveniente de quatro empresas, e na Itália, uma empresa produzia sozinha 90\% dos veículos (TOFFLER, 1980).

Segundo Bertolini (2004), o surgimento do sistema de produção enxuta no Japão revolucionou novamente a indústria automobilística ao estabelecer uma nova estrutura e organização produtiva, desenvolvida para garantir maior eficiência de produção independentemente de sua escala.

Com o reconhecimento da eficiência operacional desse novo sistema de organização da produção, que utiliza uma menor quantidade de recursos, apesar de apresentar maior flexibilidade produtiva, as empresas ocidentais passaram a utilizar o novo paradigma de produção como forma de conseguir ganhos de produtividade, qualidade, flexibilidade e, confiabilidade e custo, e atingir a eficiência operacional necessária para competir nos mercados, que tiveram suas características de competitividade acirradas devido a uma convergência dos padrões de desempenho dos produtos e serviços (BERTOLINI, 2004).

Fatores como a abertura econômica (globalização), a recessão econômica mundial, e a saturação dos mercados dos países desenvolvidos têm acirrado a concorrência mundial no setor automobilístico. Isso leva as empresas a buscarem estruturas organizacionais mais competitivas e mais compatíveis com as necessidades de cada mercado (BUIAR, 2000).

O processo de globalização torna as empresas, as regiões e os países interdependentes, permitindo que pequenas mudanças alterem suas relações, ampliando ou limitando o acesso a clientelas e restabelecendo os critérios de quem ganha e perde. Assim, a dinâmica das mudanças econômicas, tecnológicas e sociais, cria os novos modelos de organização e produção, na medida em que estabelecem a inovação e a busca constante por novos padrões de operação como as premissas do sucesso organizacional (MOTTA, 1998).

Os processos de maior relevância para o desempenho das organizações estão relacionados à identificação dos seus fatores críticos de sucesso, pois determinam o tipo de operação que deve ser priorizada pela empresa. Da mesma forma, a focalização da organização em um conjunto específico de processos, a fim de otimizar os requisitos de determinados clientes, está associada as suas escolhas estratégicas, já que elas delimitam o tipo de operação de produção a ser utilizada. O desempenho das empresas com relação a esses objetivos, depende de um conjunto de fatores relacionados às características de atuação da organização, como flexibilidade, agilidade, produtividade e qualidade, e que determinam a competitividade desta empresa (BERTOLINI, 2004).

Dessa forma, a empresa pode ter eficiência operacional, porém o desempenho de vendas pode não ter o mesmo sucesso. Assim, pode-se inferir que as empresas que possuem maior concentração industrial, não necessariamente, possuem maior participação de mercado. 
Na teoria econômica, Braga (1980) utiliza-se do conceito de concentração (distribuição do número e do tamanho relativo das firmas) para distinguir as indústrias em três categorias:

$1^{\circ}$ ) Atomizada ou concorrência equilibrada: como conseqüência do pequeno tamanho relativo e do grande número de firmas (o que afasta a possibilidade de coalizão), a produção da indústria será estendida e o preço reduzido até o ponto em que o custo marginal iguala-se ao preço;

$2^{\circ}$ ) Monopólio: a condição de vendedor único permite escolher o preço que maximiza os lucros, mediante variações do volume de produção;

$3^{\circ}$ ) Oligopólio: com poucos grandes vendedores, apresenta uma rivalidade típica entre as firmas; Porém, face à dimensão relativa de cada uma, os ajustamentos de posição por elas realizados podem afetar, perceptivelmente, os preços ou os volumes de vendas das demais firmas da indústria, aumentando a complexidade da decisão preço-produção pela necessidade de antecipar a reação dos concorrentes.

Do ponto de vista empírico, em vez de meramente distinguir as indústrias como oligopolistas ou atomísticas, o modelo tradicional sugere a classificação de várias subcategorias de indústrias oligopolistas, segundo o grau de concentração. Pode-se esperar, então, que a conduta e o desempenho dessas distintas subcategorias devam diferir conforme o nível de concentração e o grau correspondente de interdependência oligopolística. No entanto, existe uma associação inversamente proporcional entre graus de concentração e rentabilidade.

O grau de concentração industrial determinará se uma indústria específica caracteriza-se como um monopólio, oligopólio ou um mercado de concorrência equilibrada. As medidas de concentração industrial podem ser consideradas como um termômetro da concorrência das empresas de uma indústria.

A parcela ou participação de mercado, também conhecida por market share, é uma medida apresentada comumente em percentuais sobre o volume de vendas e indica sua posição no segmento.

Para abordar o tema com melhor entendimento, é relevante contextualizar a história da indústria automobilística no Brasil, segundo pesquisa bibliográfica realizada por entidades representativas desse segmento.

Quando, em 16 de junho de 1956, o então Presidente da República Juscelino Kubitschek de Oliveira ao assinar o decreto 39.412, formalizando a criação do Grupo Executivo da Indústria Automobilística (GEIA), com o objetivo de estimular a fabricação local e não somente a montagem de veículos no Brasil, certamente não teria como imaginar o vulto que aquela sua iniciativa acabaria adquirindo. Foram vinte e nove dias após a fundação da Associação Nacional dos Fabricantes de Veículos Automotores (ANFAVEA). Hoje, passados 50 anos, o setor automotivo brasileiro apresenta o maior número do mundo em montadoras instaladas 24 diferentes montadoras abastecidas por mais de quinhentas empresas de autopeças.

Trata-se de um complexo industrial com capacidade instalada para produzir 3,5 milhões de veículos e 98 mil máquinas agrícolas/ano - produtos comercializados por uma rede de 3,6 mil concessionários, espalhados por todo o território nacional. Em seu conjunto, é, agora, um setor que responde direta ou indiretamente pelo emprego de 1,3 milhão de pessoas. 
Além disso, é um setor que faturou em 2005, US\$ 42,3 bilhões - incluindo autopeças dos quais US\$ 18,1 bilhões vieram de exportações, gerando um saldo de comércio exterior de US\$ 9,2 bilhões.

Somente as montadoras contam hoje com 45 diferentes plantas industriais, distribuídas por sete Estados e vinte e seis municípios. São fábricas que produzem todos os tipos de veículos, de automóveis e comerciais leves a caminhões, ônibus, tratadores e colheitadeiras.

Veículos cuja produção e comercialização, valem ressaltar, recolheram R 21 bilhões aos cofres públicos, só no ano de 2005, com a cobrança de Imposto sobre Produtos Industrializados (IPI), Imposto sobre Circulação de Mercadorias e Prestação de Serviços (ICMS), Programa de Integração Social (PIS) e Contribuição para o Financiamento da Seguridade Social (COFINS). E são números que devem crescer ainda mais no ano de 2006, decorrência natural do já projetado crescimento nas vendas domésticas e na produção.

A implantação e desenvolvimento do setor automotivo impulsionaram o Brasil a mudar de patamar econômico. O país deixou de ter sua economia exclusivamente apoiada na agricultura e na produção de commodities primárias e passou, de fato, a ocupar lugar no chamado mundo industrializado.

O primeiro carro a rodar no Brasil foi um Peugeot, comprado em Paris, em 1893, e trazido por um engenheiro brasileiro, Henrique Dumont, pai de Alberto Santos Dumont. Desse momento até a Primeira Guerra Mundial (1914-1918), o Brasil só importou carros montados. A primeira linha de montagem apareceu em 1919, inaugurada pela Ford, que passou a produzir o modelo "T", o famoso Ford Bigode, cujas peças chegavam em caixas de madeira.

Nos anos 50, o peso do setor automotivo, além de se fazer sentir fortemente na economia, irradiava-se a vários segmentos da sociedade brasileira da época. $\mathrm{O}$ carro tornava-se objeto de desejo generalizado. Nesse mesmo período, todos assistiram à explosão da inconsciente atividade industrial brasileira, fortemente concentrada em São Paulo, e à revitalização da economia, em crise desde o declínio da atividade cafeeira. Milhões de dólares foram investidos no processo de nacionalização das montadoras. Os desafios eram enormes: falta de trabalhadores habilitados, condições precárias de estrutura viária e de comunicação, entre muitos outros.

Os 50 anos que sucedem o GEIA, foram de muitos acontecimentos no cenário políticoeconômico brasileiro e conseqüentes altos e baixos do segmento automotivo. Analisam-se aqui, as variações na concentração industrial desse mercado nos últimos onze anos (1995-2005), considerando volume de produção e sua participação nas venda no mercado nacional; além da influência de fatos de caráter histórico e (ou) estratégico bastante significativos para essas flutuações, provocados pelo ambiente externo ou interno das empresas abordadas, tal como evidencia o Quadro 1.

\begin{tabular}{|c|l|}
\hline Data & \multicolumn{1}{|c|}{ Principais acontecimentos históricos relacionados à indústria automobilística } \\
\hline 1995 & $\begin{array}{l}\text { Recorde de todos os tempos, o mercado absorve mais de 321 mil veículos importados, dos quais 266mil } \\
\text { são automóveis. Posse de Fernando Henrique Cardoso (FHC) como Presidente da República e, no } \\
\text { segundo semestre, são implementadas medidas anticonsumo para conter a inflação, dentre elas, o } \\
\text { aumento da alíquota de importação para 70\% o que afeta o mercado automobilístico, provocando } \\
\text { desaquecimento da demanda. Inflação contida e real estabilizado. }\end{array}$ \\
\hline 1996 & $\begin{array}{l}\text { O mercado automobilístico cresce 4,2\% em relação ao ano anterior. Constitui-se a Honda Automóveis do } \\
\text { Brasil, em São Paulo, sendo inaugurada no ano seguinte. }\end{array}$ \\
\hline 1997 & O setor produz 2.069.703 veículos e bate o recorde de vendas internas até hoje não igualado. \\
\hline
\end{tabular}

Revista de Negócios, ISSN 1980-4431, Blumenau, v13, n. 1, p. 93 - 107, Janeiro/março 2008. 


\begin{tabular}{|c|l|}
\hline 1998 & $\begin{array}{l}\text { A Nissan escolhe o Brasil para entrar no Mercosul. A Toyota inicia a produção do modelo Corolla. A } \\
\text { Chrysler, cuja produção encerrou-se em 2001, instala-se em Campo Largo-PR. A Renault chega a São } \\
\text { José do Pinhais-PR, sendo inaugurada no ano seguinte. }\end{array}$ \\
\hline 1999 & $\begin{array}{l}\text { O Presidente FHC consegue novo mandato na primeira reeleição do país. O ano começa com nova } \\
\text { política cambial, quando a taxa de câmbio (cotação do real perante o dólar) passa a ser flutuante. Chega a } \\
\text { Land Rover e a DaimlerChrysler passa a produzir automóveis em Juiz de Fora - MG. A Volkswagen- } \\
\text { Audi instala-se em São José dos Pinhais - PR. }\end{array}$ \\
\hline 2000 & $\begin{array}{l}\text { Em julho, a General Motors inaugura o complexo industrial de Gravataí - RS e em setembro já começa a } \\
\text { produzir o modelo Celta. A Honda lança no Brasil,a sétima geração do modelo Civic. Em outubro, é } \\
\text { constituída a Nissan do Brasil. A Fiat lança o modelo Novo Palio. A Economia apresenta sinais de } \\
\text { recuperação, bem como o mercado automobilístico. }\end{array}$ \\
\hline 2001 & $\begin{array}{l}\text { Ano em que ocorreram o atentado de 11 de setembro nos Estados Unidos e a crise energética no Brasil. A } \\
\text { PSA Peugeot Citroën instala fábrica em Porto Real - RJ e produz mais de 18 mil veículos. A Honda } \\
\text { anuncia a chegada do modelo Fit. A Ford inaugura sua fábrica em Camaçari - BA. }\end{array}$ \\
\hline 2002 & $\begin{array}{l}\text { Luiz Inácio Lula da Silva é eleito presidente. A General Motors lança o modelo novo do Corsa, em julho, } \\
\text { o modelo Celta cinco portas e em agosto, o modelo Meriva. }\end{array}$ \\
$\begin{array}{l}\text { O Brasil tem frota de 17,5 milhões de carros. A Volkswagen faz 50 anos de Brasil com mais de 13 } \\
\text { milhões de veículos produzidos. A Mitsubishi amplia a fábrica em Catalão - GO. A Honda lança o } \\
\text { modelo Fit. }\end{array}$ \\
\hline 2004 & $\begin{array}{l}\text { As vendas de veículos bicombustíveis (flex fuel) saltam para mais de 328,3 mil, quase sete vezes as de } \\
\text { 2003. A Ford adota o terceiro turno e gera 2,4 mil novos empregos. }\end{array}$ \\
\hline 2005 & $\begin{array}{l}\text { A indústria automotiva produz mais de dois milhões de automóveis e comerciais leves, colocando no } \\
\text { mercado interno 7,2\% mais autoveículos do que no ano anterior. }\end{array}$ \\
\hline $\begin{array}{l}\text { Quadro 1: Principais acontecimentos históricos na indústria automobilística } \\
\text { Fonte: ANFAVEA (2006) }\end{array}$
\end{tabular}

Para Silva (2001), até o início da década de 90, a estratégia das montadoras no Brasil estava centrada na verticalização dos fabricantes de veículos, criando um grande parque metalmecânico de autopeças, dada a abertura de mercado por meio do fortalecimento do relacionamento entre cliente e fornecedor, dividindo com isso, a responsabilidade em termos de competitividade com a indústria de autopeças.

Hoje, as montadoras procuram associar-se informalmente às firmas comprometidas com o desenvolvimento do produto até sua entrega síncrona, repartindo com isso, os lucros auferidos em função do aumento de vendas, ou os prejuízos decorrentes da falta de competitividade.

\section{METODOLOGIA DA PESQUISA}

Nesta seção apresenta-se a metodologia empregada no trabalho, sendo subdividida em três subsecções: a subseção 3.1 refere-se à caracterização da pesquisa e a subseção; a subseção 3.2 trata da forma como os dados foram coletados e tratados; a subseção 3.3 trata do método de análise usado na pesquisa.

\subsection{CARACTERIZAÇÃO DA PESQUISA}

No que tange à natureza da aplicação, esse trabalho pode ser visto como uma pesquisa aplicada, já que busca solucionar um problema concreto. Quanto aos objetivos da pesquisa, esse trabalho pode ser caracterizado como uma pesquisa descritiva, pois tal como relatam 
Ribeiro e Cruz (2004, p.18), esse tipo de pesquisa tem por objetivo estudar, analisar, registrar e interpretar os fatos do mundo físico sem a interferência do pesquisador.

Esta pesquisa também pode ser caracterizada quanto à aquisição de referências bibliográficas, como uma pesquisa bibliográfica cuja finalidade é conhecer algumas contribuições científicas na área do turismo. Oliveira $(2000$, p. 19) ressalta que a pesquisa bibliográfica acaba se transformando em rotina para os pesquisadores e profissionais que necessitam de constante atualização. A pesquisa pode ainda ser caracterizada em função do Tempo de coleta, nesse caso, o referido trabalho pode ser visto como um Estudo de natureza longitudinal.

\subsection{COLETA DE DADOS}

Foram coletados dados de produção e venda de veículos para passageiros e de uso misto junto à ANFAVEA (2006), referentes ao período compreendido entre 1995 e 2005 das empresas fabricantes de veículos automotores. Devido à variedade de tipos produzidos, foi selecionado o tipo de veículo para passageiros e de uso misto por apresentar uma quantidade maior de bens de consumo disponíveis à população. Já os valores de faturamento considerados referem-se a vendas internas de veículos nacionais no atacado, uma vez que a indústria automobilística, no período avaliado, não efetuava vendas diretas ao consumidor, com volume significativo.

\subsection{MÉTODO DE ANÁLISE}

Para a mensuração da concentração industrial no setor automobilístico brasileiro, foram utilizadas três medidas de concentração, a saber: Razão de Concentração (CR), Índice de Hirschman-Herfindahl (IHH) e Índice de Rosenbluth (B).

$\mathrm{Na}$ avaliação das medidas de concentração industrial foi utilizado como suporte inicial o valor da produção anual de veículos de cada empresa do setor " $\mathrm{y}_{\mathrm{i}}$ ", a fim de identificar a participação da i-ésima empresa no valor da produção da indústria, tal como pode ser mensurado a partir da expressão (1).

$$
\mathrm{y}_{\mathrm{i}}=\frac{\mathrm{x}_{\mathrm{i}}}{\eta \mu}
$$

Onde:

$\mathrm{y}_{\mathrm{i}}$ : o valor relativo da participação da empresa no ano $i$;

$\mathrm{X}_{\mathrm{i}}$ : valor da produção da $i$-ésima empresa;

$\eta$ : número de empresas que fazem parte de indústria

$\mu$ : valor médio da produção 
Supondo-se que as empresas encontrem-se ordenadas de tal forma que $\mathrm{X}_{1} \geq \mathrm{X}_{2} \geq \mathrm{X}_{3}$ $\geq \ldots \geq X_{n}, \operatorname{logo}$, a Razão de Concentração $(\mathrm{CR})$ das "k" maiores empresas é obtida por meio da equação (2).

$\mathrm{CR}_{\mathrm{k}}=\sum_{\mathrm{i}=1}^{\mathrm{k}} \mathrm{y}_{\mathrm{i}}$

Cabe salientar que, na teoria econômica, o valor de $\mathrm{k}=4$ é o mais comumente usado em alguns ambientes de produção industrial como forma de identificar comportamento oligopolístico das quatro maiores empresas (HOFFMAN, 2006). O Índice de HirschmanHerfindahl (IHH) pode ser expresso a partir da equação (3).

$$
\mathrm{IHH}=\sum_{\mathrm{i}=1}^{\mathrm{n}} \mathrm{y}_{\mathrm{i}}^{2}
$$

O valor máximo do índice denotado em (3) ocorre quando a indústria é constituída por uma única empresa, isto é: $\mathrm{IHH}=1$. Seu valor se aproxima de zero quando todos os " $\mathrm{y}_{\mathrm{i}}$ " são diminutos, isto é, quando a produção está dividida de forma relativamente igualitária por um grande número de empresas.

O Índice de Rosenbluth (B) pode ser definido, considerando que as empresas de uma indústria estejam ordenadas de maneira que $\mathrm{y}_{1} \geq \mathrm{y}_{2} \geq \mathrm{y}_{3} \geq \ldots \geq \mathrm{y}_{\mathrm{n}}$ pode ser mensurado por meio da equação (4).

$$
\mathrm{B}=\frac{1}{2 \sum_{\mathrm{i}} \mathrm{y}_{\mathrm{i}}-1}
$$

Quando a indústria é constituída por uma única empresa, $\mathrm{B}=1$, isto é, o índice de Rosenbluth atinge seu valor máximo. $\mathrm{O}$ índice se aproxima de zero quando a produção está dividida de maneira relativamente igualitária por um grande número de empresas. Foram escolhidas três medidas de concentração industrial por não haver elementos conclusivos que permitam a escolha entre os vários índices (BRAGA, 1980).

O grau de concentração de uma indústria tende a ser tão maior quanto menor for o número de empresas que o setor. Assim, por exemplo, se existe um cenário onde duas empresas detêm oitenta por cento da produção de um segmento, pode-se dizer que se tem uma situação de oligopólio.

Para verificar o market share de cada empresa da indústria automobilística, realiza-se uma comparação da participação relativa de cada firma com relação ao total de vendas realizadas no período analisado. Neste caso, faz-se uma análise da proporção em termos percentuais de cada empresa com relação a sua participação sobre a produção total com relação a sua participação percentual sobre as vendas. 


\section{APRESENTAÇÃO E ANÁLISE DOS DADOS}

Foram coletados os dados de produção e vendas das empresas da indústria automobilística no intervalo de 1995 a 2005. Para cada ano analisado, calcularam-se os índices de concentração, considerando a participação relativa de cada empresa no volume de vendas e da produção, assim como a razão de concentração das quatro maiores firmas.

Por meio do cálculo anual, pode-se observar uma variação dos índices bem como o aumento de empresas atuantes na indústria e a chegada de novas entrantes. Ficou evidenciado também o encerramento de atividades de algumas empresas entrantes no período, atuantes nos setores de veículos de passeio e de uso misto.

Em uma análise inicial, efetuou-se ainda o cálculo da média e desvio padrão da amostra, visando verificar a necessidade de ajuste nos dados amostrais. Esse procedimento, conforme citado por Hoffmann (apud MARCONI, 1999), constitui-se em "um dos procedimentos para a redução dos dados, expressando valores que se encontram situados entre extremos de uma série ou distribuição".

Considerando os resultados obtidos para a média aritmética e o desvio padrão dos volumes no período avaliado - produção e vendas -, e os objetivos propostos pelo trabalho, optou-se por analisar os valores de todas as empresas participantes da indústria automobilística, produtora de veículos de passeio e de uso misto. Os resultados obtidos para identificar o grau de concentração da indústria automobilística são demonstrados na Tabela 1.

\begin{tabular}{c|c|c|c}
\hline \multicolumn{5}{c}{ Tabela 1: Índices de Concentração na produção de veículos de passageiros e de uso misto } \\
\hline Ano & CR4 & IHH & B \\
\hline 1995 & $100,00 \%$ & $29,59 \%$ & $32,77 \%$ \\
\hline 1996 & $100,00 \%$ & $30,11 \%$ & $32,86 \%$ \\
\hline 1997 & $99,95 \%$ & $28,46 \%$ & $30,97 \%$ \\
\hline 1998 & $98,59 \%$ & $27,14 \%$ & $29,44 \%$ \\
\hline 1999 & $94,14 \%$ & $26,04 \%$ & $27,44 \%$ \\
\hline 2000 & $91,35 \%$ & $25,49 \%$ & $27,37 \%$ \\
\hline 2001 & $90,12 \%$ & $25,24 \%$ & $27,12 \%$ \\
\hline 2002 & $90,72 \%$ & $24,06 \%$ & $26,61 \%$ \\
\hline 2003 & $87,99 \%$ & $22,60 \%$ & $25,37 \%$ \\
\hline 2004 & $86,91 \%$ & $22,51 \%$ & $23,55 \%$ \\
\hline 2005 & $86,51 \%$ & $22,02 \%$ & $23,24 \%$ \\
\hline
\end{tabular}

Nota: Os resultados dos cálculos dos índices de concentração estão expressos em termos de porcentagem.

Observa-se, a partir da Tabela 1, que a razão da concentração (CR) não foi influenciada pelo número de empresas que fazem parte da indústria, o que mostra que as quatro maiores empresas detêm a maior proporção do valor total da produção do setor, variando de $100 \%$ nos primeiros anos da análise até aproximadamente $86 \%$ nos últimos anos, o que caracterizaria um oligopólio, isso também evidencia a presença de um aumento de produção das demais empresas que fazem parte da indústria automobilística de veículos para passeio e de uso misto.

Os índices IHH e B indicam que havia um grau maior de concentração industrial entre 1995 e 1998, quando existiam somente 4 (quatro) empresas atuando no setor. Com a entrada de 5 (cinco) novas montadoras: Toyota, Renault, Mercedes Benz, DaimlerChrysler e Peugeot Citroen, entre os anos de 1999 e 2001, o grau de concentração apresenta um decréscimo nos 
anos seguintes. A Figura 1 permite visualizar a esta evolução da concentração no período avaliado.

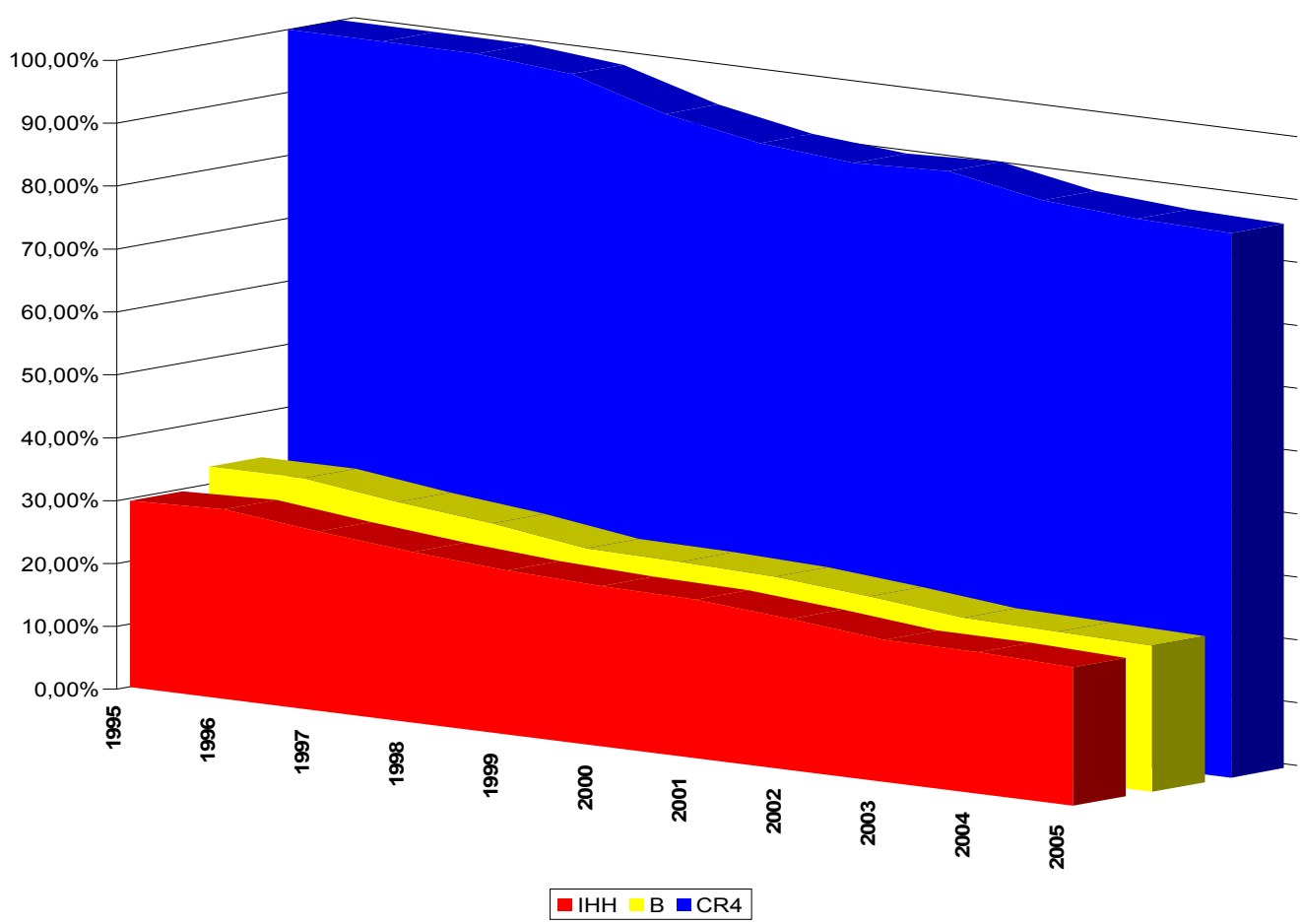

Figura 1: Grau de Concentração do Mercado Automobilístico Brasileiro

$\mathrm{Na}$ Tabela 2, são apresentados não só os percentuais das vendas da indústria automobilística brasileira no atacado e sua relação com o total da produção ano a ano no período analisado, como as taxas de variação das vendas e da produção.

Tabela 2: Percentual da produção e das vendas efetuadas entre 1995 e 2005

\begin{tabular}{c|c|c|c|c|c}
\hline Ano & $\begin{array}{c}\text { Produção } \\
\text { (Unid.) }\end{array}$ & Vendas (Unid.) & $\begin{array}{c}\text { Var. Produção } \\
\mathbf{( \% )}\end{array}$ & $\begin{array}{c}\text { Var. Vendas } \\
\mathbf{( \% )}\end{array}$ & $\begin{array}{c}\text { Partic. } \\
\text { Vendas/Produção } \\
\mathbf{( \% )}\end{array}$ \\
\hline 1995 & 1.297 .467 & 1.106 .591 & - & - & 85,29 \\
\hline 1996 & 1.458 .576 & 1.245 .972 & 12,42 & 12,60 & 85,42 \\
\hline 1997 & 1.677 .858 & 1.361 .106 & 15,03 & 9,24 & 81,12 \\
\hline 1998 & 1.254 .016 & 967.055 & $-25,26$ & $-28,95$ & 77,12 \\
\hline 1999 & 1.109 .509 & 898.584 & $-11,52$ & $-7,08$ & 80,99 \\
\hline 2000 & 1.281 .403 & 1.071 .201 & 15,49 & 19,21 & 83,60 \\
\hline 2001 & 1.349 .984 & 1.176 .557 & 5,35 & 9,84 & 87,15 \\
\hline 2002 & 1.520 .285 & 1.163 .717 & 12,62 & $-1,09$ & 76,55 \\
\hline 2003 & 1.533 .613 & 1.082 .328 & 0,88 & $-6,99$ & 70,57 \\
\hline 2004 & 1.862 .780 & 1.263 .447 & 21,46 & 16,73 & 67,83 \\
\hline 2005 & 2.009 .494 & 1.329 .794 & 7,88 & 5,25 & 66,18 \\
\hline TOTAL: & 16.354 .985 & 12.666 .352 & 54,34 & 28,75 & - \\
\hline
\end{tabular}

Fonte: ANFAVEA (2006).

Revista de Negócios, ISSN 1980-4431, Blumenau, v13, n. 1, p. 93 - 107, Janeiro/março 2008. 102 
Pode-se observar, por meio da Tabela 2, que o volume de produção teve uma desaceleração nos anos de 1998 e 1999, respectivamente, em função das incertezas econômicas vivenciadas à época, que se refletiram na oferta e demanda por veículos de passeio e de uso misto. A partir do ano 2000, a taxa de crescimento do volume de produção apresentou crescimentos significativos, destacando-se o ano de 2004, quando cresceu aproximadamente 21,46\%. Já em termos globais, verifica-se que a produção cresceu em torno de 54,34\%.

No tocante às vendas, verifica-se ainda, que os anos de 2002 e 2003 registraram uma queda no seu crescimento, dado que apresentou taxas negativas de 1,09\% e 6,99\%, respectivamente. Nesse mesmo período, tanto as vendas de automóveis para o mercado externo, como a capacidade instalada da indústria foram reduzidas, demonstrando claros sinais de uma economia recessiva.

Também se observa que a relação entre o volume de vendas e a produção no mesmo período, que era de $82,29 \%$ no ano de 1995 , passou para $66,18 \%$ no ano de 2005 , o que representa uma retração nas vendas do mercado interno de aproximadamente 19,11\% nesse mesmo período.

Avaliando-se o desempenho das vendas segmentado pelas empresas componentes da indústria automobilística, tal como se encontra no Quadro 1, também pode ser observado que o percentual da participação no mercado em relação às vendas não necessariamente reflete a sua participação no total produzido. Percebe-se a partir da montadora Volkswagen que, apesar de ser a maior produtora de veículos e a maior em vendas, apresenta uma porcentagem menor de vendas $29,80 \%$ contra os $32,71 \%$ da produção. Essa diferença demonstra que a empresa, embora seja líder de mercado, não consegue atingir em vendas o mesmo percentual de participação que apresenta na produção.

\begin{tabular}{|l|c|c|c|c|}
\hline \multicolumn{1}{|c|}{ Motadores } & $\begin{array}{c}\text { Total } \\
\text { Vendas }\end{array}$ & $\begin{array}{c}\text { Total } \\
\text { Produção }\end{array}$ & $\begin{array}{c}\text { Participação } \\
\text { relativa sobre as } \\
\text { vendas (\%) }\end{array}$ & $\begin{array}{c}\text { Participação } \\
\text { relativa sobre a } \\
\text { producão (\%) }\end{array}$ \\
\hline Volkswagem do Brasil LTDA. & 3.777 .310 & 5.349 .091 & 29,80 & 32,71 \\
\hline General Motors do Brasil LTDA. & 3.228 .524 & 4.160 .642 & 25,47 & 25,44 \\
\hline Fiat Automóveis S.A. & 3.644 .058 & 4.321 .348 & 28,75 & 26,42 \\
\hline Ford Brasil LTDA. & 1.020 .875 & 1.356 .090 & 8,05 & 8,29 \\
\hline Peugeot Citroen do Brasil S.A. & 225.310 & 264.387 & 1,78 & 1,62 \\
\hline Honda Automóveis do Brasil LTDA. & 235.114 & 253.757 & 1,85 & 1,55 \\
\hline Toyota do Brasil LTDA. & 176.329 & 208.185 & 1,39 & 1,27 \\
\hline Renault do Brasil Automóveis S.A. & 318.374 & 378.083 & 2,51 & 2,31 \\
\hline Daimlerchrysler do Brasil LTDA. & 31.650 & 33.413 & 0,25 & 0,20 \\
\hline Mercedes-Benz do Brasil S.A. & 17.206 & 29.989 & 0,14 & 0,18 \\
\hline Total & 12.674 .750 & 16.354 .985 & 100,00 & 100,00 \\
\hline
\end{tabular}

Quadro 1: Percentual das vendas por empresa em relação à produção

Observa-se também no Quadro 1 que, embora tenham entrada novas montadoras, o total da produção e de vendas das seis empresas menores equivale à quase totalidade dos volumes obtidos pela quarta maior empresa do setor.

Nos últimos anos, as montadoras desse setor adotaram uma política de antecipação da demanda, prevendo assim, um aumento na demanda por automóveis. As novas formas de organização flexíveis do processo produtivo, combinadas com os equipamentos de base 
microeletrônica, viabilizam a obtenção de maior eficiência e produtividade, ampliando de forma significativa a capacidade competitiva da indústria.

Percebe-se ainda, a existência da modernização tecnológica da indústria automobilística por meio da utilização de robôs, máquinas-ferramentas com comando numérico, controladores lógicos programáveis e sistemas de desenhos auxiliados por computador. Esses equipamentos permitem automatizar as plantas industriais desde o desenho do produto até sua fabricação, proporcionando melhor qualidade, maior versatilidade e flexibilidade da produção, maior controle sobre as linhas de montagem e redução do tempo de produção.

Cabe destacar que, nessa indústria, as transformações que se deram após 1990 obrigaram as empresas do setor a um intenso processo de reestruturação, obtendo um aumento da produtividade por meio de inovações na gestão e de maior automação da linha produtiva, com a conseqüente redução do número de postos de trabalho. $\mathrm{O}$ volume de empregos diretos e indiretos gerados pelas empresas do setor automobilístico em sua expansão no mercado brasileiro é muito baixo.

Nota-se ainda, que a disputa por esse mercado nacional encontra-se calcada no crescimento da demanda, a qual é conquistada não somente pelo preço, mas também a diferenciação e inovação do produto. As principais barreiras à entrada nesse mercado referemse à escala técnica, em função do volume mínimo necessário para que um novo concorrente tenha preços competitivos, diferenciação do produto, características técnicas criadas principalmente pelo mercado automotivo.

A vantagem competitiva nesse mercado passou a ser avaliada em função da capacidade que a empresa possui para gastar menos e oferecer mais, por meio do melhor uso das técnicas de produção, tal como a terceirização, e cooperativas, como o desenvolvimento de fornecedores sistêmicos.

Já em relação à concentração e (ou) desconcentração espacial da indústria automobilística brasileira, percebeu-se que os incentivos fiscais concedidos pelo estado acabaram interferindo de maneira decisiva na localização das montadoras no território nacional. O controle das decisões na alocação dos recursos públicos foi apresentado ao país como uma nova política industrial para o setor automotivo, constituindo-se num conjunto de incentivos à instalação de novas unidades produtivas, bem como à exportação do setor, sem haver como contrapartida a preocupação com o estímulo ao repasse de tecnologia do exterior para o Brasil ou mesmo de se criar novos postos de trabalho.

Finalmente, sobre os resultados para os índices de concentração industrial, pode-se dizer que a estrutura de mercado avaliada é um oligopólio diferenciado-concentrado, uma vez que se caracteriza por possuir um elevado grau de concentração, com aproximadamente 95\% do mercado sendo controlado por cinco fabricantes, a saber: Volkswagem, General Motors, Fiat, Ford e Renault.

\section{CONSIDERAÇÕES FINAIS}

O objetivo deste trabalho foi avaliar o grau de concentração da indústria automobilística no Brasil, investigando concomitantemente, se existe relação entre os índices de concentração e sua participação no mercado. Esta análise considerou a produção e venda de veículos de passageiros e leves no período de 1995 a 2005, e sua efetiva participação no mercado nacional.

Revista de Negócios, ISSN 1980-4431, Blumenau, v13, n. 1, p. 93 - 107, Janeiro/março 2008. 104 
Buscou-se mostrar ainda, a influência de fatos de caráter histórico e estratégico bastante significativos para flutuações como, por exemplo, a entrada de novas concorrentes.

Foram coletados dados de produção e venda de veículos para passageiros e de uso misto junto à ANFAVEA (2006), no período compreendido entre 1995 e 2005), das empresas fabricantes de veículos automotores. Devido à variedade de tipos produzidos, foi selecionado o tipo de veículo para passageiros e de uso misto por apresentar uma quantidade maior de bens de consumo disponíveis à população.

Para a mensuração da concentração industrial no setor automobilístico brasileiro, foram utilizadas três medidas de concentração, a saber: Razão de Concentração (CR), Índice de Hirschman-Herfindahl (IHH) e Índice de Rosenbluth (B).

A análise levou à constatação de uma elevada razão de concentração no início do período da análise que vai diminuindo na medida em que novas empresas são implantadas no setor e, gradativamente, vão aumentando sua quantidade de produção e, conseqüentemente, sua participação no mercado.

Entretanto, embora haja novas entrantes, pode-se dizer que no setor ainda predomina o oligopólio com o domínio das quatro principais empresas: Fiat, Volkswagen, General Motors e Ford. Essa diminuição da concentração também está refletida pelos índices $\mathrm{H}$ e $\mathrm{B}$ que evidenciam uma diminuição da concentração industrial com a entrada de novas empresas.

Embora o estudo evidencie um oligopólio, mostra também que esse fator não se tornou impeditivo para a entrada de novas concorrentes na indústria automobilística no final da década de 90. A produção das novas indústrias veio a beneficiar o consumidor brasileiro, que passou a ter maiores opções de escolha no segmento. Contudo, vale salientar que a oferta e demanda não foram objeto de estudo neste trabalho.

Por outro lado, a análise dos dados de vendas e produção por empresa e sua relação com o total, demonstrou que, embora algumas empresas, na relação participação sobre o total de vendas e sobre o total da produção, não mantiveram a mesma proporção percentual. Algumas empresas apresentaram uma participação relativa sobre as vendas melhor que a participação relativa sobre a produção.

\section{REFERÊNCIAS}

ARAUJO, L. C. G. Organização, Sistemas e Métodos e as Modernas Ferramentas de Gestão Organizacional. $2^{a}$ tiragem. São Paulo: Atlas, 2001.

BERTOLINI, V. Os Fatores Críticos de Sucesso na Indústria de Autopeças no Brasil: um estudo exploratório dos níveis hierárquicos da cadeia de fornecedores da indústria automobilística. 2004. 130 fls. Dissertação (Mestrado em Engenharia de Produção) Departamento de Engenharia de Produção e Sistemas, Universidade Federal de Santa Catarina, Florianópolis.

BUIAR, D. R. Vantagem Competitiva da Flexibilidade via Tecnologia de Informação : Um Modelo de Auditoria e Estudo de caso no Pólo Automotivo Paranaense. 2000. 194f.. Tese (Doutorado em Engenharia de Produção) - Departamento de Engenharia de Produção e Sistemas, Universidade Federal de Santa Catarina, Florianópolis.

Revista de Negócios, ISSN 1980-4431, Blumenau, v13, n. 1, p. 93 - 107, Janeiro/março 2008.105 
BRAGA, H. C. Estrutura de Mercado e Desempenho da Indústria Brasileira: 1973-75. $1^{\mathrm{a}}$ edição. Rio de Janeiro: Fundação Getúlio Vargas, 1980.

CARVALHO, Paulo Gonzaga M.; FEIJO, Carmem Aparecida; RODRIGUEZ, Maristella Schaefers. Concentração Industrial e Produtividade do Trabalho na Indústria de Transformação nos anos 90: evidências empíricas. Revista Economia. Niterói: ANPEC, v.4, n.1, p. 19-52, 2003.

FERREIRA, A. A.; REIS, A. C. F.; PEREIRA, M. I. Gestão Empresarial: de Taylor aos Nossos Dias. São Paulo: Thomson, 1998.

GEORGE, Kenneth D.; JOLL, Caroline. Organização Industrial: concorrência, crescimento e mudança estrutural. Rio de Janeiro: Zahar Editores, 1983.

HOFFMANN, R. Estatística para Economistas. $\quad 4^{\mathrm{a}}$ edição revista e ampliada. São Paulo: Thomson, 2006.

INDÚSTRIA AUTOMOBILÍSTICA BRASILEIRA: 50 ANOS. Publicação: Anuário comemorativo da ANFAVEA. 2006.

INDÚSTRIA AUTOMOBILÍSTICA NO BRASIL BNDES. Disponível em:

http://www.bndes.gov.br/conhecimento/setorial/get2is11.pdf\#search='industria\%20automobilis tica\%20no\%20brasil'. Acesso em 11/08/2006.

MARCONI, M. A. Técnicas de Pesquisa: planejamento e execução de pesquisas; Amostragens e técnicas de pesquisa; Elaboração, análise e interpretação de dados. São Paulo;Atlas, 1999.

MOTTA, P. A. Transformação Organizacional. Rio de Janeiro: Qualitymark, 1998.

OLIVEIRA, Silvio L. Tratado de metodologia científica: projetos de pesquisas, TGI, TCC, Monografias, Dissertações e Teses, 2 ed., São Paulo: Pioneira, 2000.

RAMOS, A. G. A nova ciência das organizações: Uma Reconceituação da Riqueza das Nações. 2a edição. Rio de Janeiro: FGV Instituto de Documentação, 1989.

RIBEIRO, Uirá; CRUZ, Carla. Metodologia Científica: teoria e prática. $2^{\mathrm{a}}$ ed., Rio de Janeiro: Axcel Books do Brasil Editora, 2004.

Site ANFAVEA.- www.anfavea.com.br. Acesso em 15/08/2006.

SILVA, Christian Luiz. Competitividade e Estratégia Empresarial: Um Estudo de Caso da Indústria Automobilística Brasileira na Década de 1990. Revista da FAE, Curitiba, v. 4, n. 1, p. 35-48, jan./abr., 2001.

TOFFLER, A. A Terceira Onda. 4 ed. Rio de Janeiro : Record, 1980.

Revista de Negócios, ISSN 1980-4431, Blumenau, v13, n. 1, p. 93 - 107, Janeiro/março 2008. 106 
ANÁLISE DO GRAU DE CONCENTRAÇÃO DA INDÚSTRIA AUTOMOBILÍSTICA BRASILEIRA E SUA RELAÇÃO COM A PARTICIPAÇÃO NO MERCADO

WOMACK, P.J.; JONES, D.T.; ROSS D. A Máquina que Mudou o Mundo. Rio de Janeiro: Campus, 1992. 